\title{
CORRESPONDENCE
}

\section{Passive smoking and asthma death}

\section{To the Editors:}

In 1998 during a flight from Athens (Greece) to San Francisco (CA, USA), A.M. Hanson, an asthmatic doctor aged 52 yrs, died due to an asthmatic reaction to second-hand cigarette smoke. In 2004, the US Supreme Court ruled that Olympic Airways was to pay the widow of A.M. Hanson US $\$ 1.4$ million. This successful lawsuit by a passenger against an airline over smoking was unprecedented, and smoking on aeroplanes has become rare since the tragic incident occurred $[1,2]$. A similar sudden death occurred in 1999, when Monica C., a 35-yr-old asthmatic, died from an acute asthma attack while working in the Paribas Bank in Milan (Italy). Asthma death was confirmed at autopsy. Monica C. had been hired by the bank under a programme providing tax incentives to employers who hire staff with physical handicaps, in this case severe asthma. She had complained for several months about the deleterious effects of second-hand cigarette smoke in her workplace and had requested several times to be moved to a smokefree office. In 2006, after a long and inconclusive lawsuit, in which the present authors were the plaintiff's expert witnesses, the bank offered a monetary settlement to the victim's family (husband and son), who accepted the settlement and suspended any legal action [3].

While asthmatics are advised to avoid passive smoking [4], there is no firm evidence to suggest that second-hand smoke may trigger an asthma attack. However, these two cases suggest that second-hand smoke can indeed trigger fatal attacks of asthma and that asthmatics should always be guaranteed a smokefree environment.

\author{
G. Invernizzi*, R. Boffi* A. Ruprecht*, A. Lazzaro ${ }^{*}$ and \\ L.M. Fabbri \\ *Tobacco Control Unit, Instituto Nazionale dei Tumori/SIMG, \\ \#Forensic Medicine Institute, Università Statale, Milan, and \\ "Respiratory Diseases Dept, Università di Modena e Reggio \\ Emilia, Italy.
}

\section{STATEMENT OF INTEREST}

None declared.

\section{REFERENCES}

1 Charatan F. Supreme Court holds airline liable for doctor's death. BMJ 2004; 328: 544.

2 Sweda EL Jr. Lawsuits and secondhand smoke. Tob Control 2004; 13: Suppl. 1, i61-i66.

3 Tribunale del Lavoro di Milano, Causa n. RG 5416/2002, verbale di conciliazione n. cron. 661 del 7/3/2006. [Labour Courts of Nilan, case n. RG541612002, minutes of conciliation $661,07 / 03 / 2006$.]

$4 \mathrm{WHO} /$ NHLBI Workshop report. Global strategy for asthma management and prevention. Publication Number 02-3659. National Institutes of Health, National Heart, Lung and Blood Institute, 2002. www.ginasthma.com Date last accessed: November 30, 2007. Date last updated: October $15,2007$.

DOI: $10.1183 / 09031936.00082008$

\section{Exacerbations and intent-to-treat analyses in randomised trials}

\section{To the Editors:}

The recent paper by KEENE et al. [1] that reviews different approaches for the analysis of exacerbation rates is valuable because of the central role of exacerbations in evaluating the benefits of drugs in chronic obstructive pulmonary disease (COPD) trials [1]. The authors present reanalyses of the TRISTAN (Trial of Inhaled Steroids and Long-acting $\beta_{2}$-agonists) and ISOLDE (Inhaled Steroids in Obstructive Lung Disease in Europe) trial data, which have been previously identified as incorrectly analysed because of the absence of consideration for between-subject variability in exacerbation rates [2]. With the proper reanalyses, their conclusions from these trials remain the same; namely that inhaled corticosteroids (ICSs) with or without long-acting $\beta$-agonists reduce the frequency of exacerbations in patients with COPD. While the data reanalyses per se are appropriate, it is important to remember that two major imperfections in the study design of these trials could have led to flawed data and thus biased results.

First, the TRISTAN and ISOLDE trials did not follow patients until the end of the study, only until the patients discontinued the study drug, so that any exacerbation data beyond that point were missing. Consequently, the fundamental intent-totreat analysis was not achievable. KEENE et al. [1] correctly note that the Poisson methods do not account for the fact that 